\title{
Bernd Bölscher, Hitlers Marine im Landkriegseinsatz. Eine Dokumentation, Norderstedt: Books on Demand 2015, 420 S., EUR 28,80 \\ [ISBN 978-3-7386-3509-6]
}

Besprochen von Dieter Hartwig: Kiel, E-Mail: Dieter-Hartwig@kielnet.net

DOI 10.1515/mgzs-2016-0121

Während der Kenntnisnahme - für eine Lektüre war zu wenig echter Lesestoff! des vorliegenden Buches, verfolgte den Rezensenten dauerhaft die Frage: Wer benötigt ein solches Buch? Die Titelformulierung weckt Interesse hinsichtlich einer Geschichte z.B. der Marinedivisionen, Infanterie- und Schützeneinheiten, die beispielsweise im »Weltkriegswerk« (Das Deutsche Reich und der Zweite Weltkrieg, 10 Bde, München 1979-2008) des Militärgeschichtlichen Forschungsamtes (jetzt: Zentrum für Militärgeschichte und Sozialwissenschaften der Bundeswehr) oder von Ulrich Saft in dem Buch »Krieg in der Heimat« (Langenhagen 1992) zwar verstreut erwähnt werden, zu denen aber eine zusammenhängende wissenschaftliche Gesamtdarstellung fehlt. Der Untertitel allerdings weist eher in die Richtung des Erwartbaren: »Dokumentation - Truppenteile - Personen Chronologie - Bilder«. Tatsächlich will der Autor »eine Lücke schließen im Schrifttum über die deutsche Kriegsmarine im Zweiten Weltkrieg «, wo ja tatsächlich die (infanteristischen) Landeinheiten naturgemäß kaum vorkommen. Es geht ihm um ein "Kompendium über die Geschichte der Landkriegseinsätze und [daran] beteiligte Personen« (S. 4). »Kompendium« - das ließe den Leser einen "Abriss, kurzgefasstes Lehrbuch" erwarten. Tatsächlich aber erhält er: auf zwei Seiten in Teil 1 eine Einführung, d.h. eine knappe Übersicht der verschiedenen 
Einrichtungen und Einsatzorte, worin eine sehr kurze Linie gezogen wird vom Ende des Ersten Weltkrieges bis hin zur »von Dönitz ausgegebenen Parole der bedingungslosen >Treue zum Führer « und der "Hitler-Raederschen Aufrüstung " (S. 5). Erwähnt werden die »wenig erfolgreichen« ersten Kampfeinsätze schon in Danzig, dann in Norwegen, spätere Einsätze z.B. am Asowschen Meer, Dönitz' Einfluss auf Hitlers Entscheidung, die Krim zu halten, sowie der allzu späte Abzug der Kurlandarmee und zuletzt Dönitz' »Paradigmenwechsel«, nämlich zusätzlich zur Seekriegführung auch die Landkriegführung als Aufgabe der Marine anzuerkennen.

Das ist alles richtig, aber auch reichlich bekannt, und es bleibt die Frage, was die nächsten 410 Seiten Neues bringen. Die Antwort lautet: Nach dem Vorbild von Walter Lohmann und Hans Hildebrand (Die deutsche Kriegsmarine 1939-1945, 3 Bde, Bad Nauheim 1964) in »Teil 2: Truppenteile der Ausbildungs- und Ersatzorganisation der Kriegsmarine« auf 22 Seiten die Aufzählung aller Landeinheiten der Kriegsmarine samt ihres Leitungspersonals, in »Teil 3« die Aufzählung der »Marschverbände« (4 S.) und in »Teil 4« die der »Landeinheiten der Stützpunktund Hafenverteidigung« (9 S.) im Bereich der Kommandierenden Admirale Schwarzes Meer, Ägäis und Adria sowie Marinekommando Italien. Wer es noch nicht wusste, wird sich wundern, wo überall sich deutsche Truppen im Zweiten Weltkrieg »aufhielten«. Das gilt auch für die Aufzählung in »Teil 5: Landkampfverbände« (61 S.), deren Dislozierung sich von »5.1 Westeuropa 1942-1945« bis $\mathrm{zu}$ »5.8 Marine-Einsatzkommandos« z.B. in Griechenland und Jugoslawien erstreckte. »Weitere Marinetruppen des letzen Aufgebots« (S. 93) weisen auf den Irrsinn insbesondere des Kriegsendes hin; allerdings auch auf die Zweifelhaftigkeit dieser Fleißarbeit: »Marine-Schützen-Bataillon 901 gemäß DRK-Liste MB308 ein vermisster Soldat bei Neubrandenburg im April 1945« (S. 93). Die Angaben in »Teil 6: Kennziffern zur Identifizierung von Truppenteilen«, darin Feldpostnummern und DRK-Liste (11,5 S.), mögen auch 70 Jahre nach Kriegsende evtl. noch hilfreich sein, was auch gelten könnte für die Angaben in »Teil 7: Verzeichnis der Offiziere mitsamt Werdegang « (230 S.). Letztere sind jedoch großenteils von Lohmann/Hildebrand abgeschrieben worden und ebenso oft von nur geringem Aussagewert, da die Angaben mal mit, mal ohne Lebensdaten und/oder CrewZugehörigkeit erfolgen. »Teil 8: Chronologie« (47 S.) entspricht der »Chronik des Seekrieges 1939-1945 (Jürgen Rohwer und Gerhard Hümmelchen, Oldenburg, Hamburg 1968). Wie diese eine Darstellung des Seekrieges nicht ersetzte, kann Bölschers Chronologie des Landkriegseinsatzes der Marine nicht als Darstellung eben dieser Ereignisse gelten. Immerhin nimmt man aus dieser eher eklektischen Zusammenstelltung u.a. interessiert zur Kenntnis, dass eine Marinelandeinheit als »Landungskorps« schon 1938 auf dem Panzerschiff »Deutschland « für den Spanischen Bürgerkrieg eingeschifft wurde und die »1. Marine-Stoßtrupp- 
Kompanie [...] bei der Besetzung des Memellandes« am 23. März 1939 mitwirkte. Das allerdings und vieles andere wurde dem Sachbuch »Deutsche Marineinfanterie 1939-1945: Das Schicksal der Marinestoßtrupps, der M.A.A. 531 (von Diest) und anderer infanteristisch eingesetzter Einheiten der Kriegsmarine« (Jörg Benz, Husum 1996, ebenfalls mit einer Chronologie, aber im Titel irreführend) entnommen.

Die Abbildungen in »Teil 9: Bilder« reichen von der (marinetypisch) dilettantisch anmutenden Landkampfausbildung am Strand von Norderney über Zerstörungen der Westerplatte am 1. September 1939 bis hin zum »Deutschen Soldatenfriedhof Neumark (Glienna, Polen) im November 2014«, gefolgt von »Teil 10: Soldatenfriedhöfe mit gefallenen Marineangehörigen« in Deutschland und Europa. Die in »Teil 11. Dokumente« wiedergegebenen Quellen können auch nur exemplarischen Charakter haben - nur wofür bzw. für welchen Erkenntnisgewinn des Lesers?

Das letzte Dokument vor dem Quellenverzeichnis, nämlich ein Todesurteil wegen Fahnenflucht gegen einen Matrosen noch am 28. April 1945, bei dem ein im siebten Teil aufgeführter Kompaniechef als Ankläger fungierte, bestätigt nur einmal mehr, wie sehr das »Nie wieder ein November 1918« das Handeln nicht nur des Großadmirals Dönitz bestimmte. Besonders zynisch berührt der letzte Satz auch dieses Todesurteils, wonach »neben dieser Strafe auf Verlust der Wehrwürdigkeit und Verlust der bürgerlichen Ehrenrechte auf Lebenszeit erkannt« (S. 416) wurde.

Vier Seiten »Quellen « (Bücher, Zeitschriften, gedruckte und ungedruckte Quellen) beschließen den Nachweis bestimmt unendlicher Sammeltätigkeit und ebensolchen Fleißes, deren Erkentnnisgewinn dem Rezensenten aber verschlossen blieb. Allenfalls einigen wenigen von »Familienforschern« angefragten Einrichtungen (Archive, Museen, Bibliotheken) mag eine solche Dokumentation als Suchund Fundort helfen. So sahen es wohl auch die einschlägigen Fachverlage, weshalb allein eine Publikation als Book on Demand möglich war, mit dem Risiko, dass das Buch weitgehend unbeachtet bleibt bzw. - sofern doch des irreführenden Titels wegen gekauft - verärgert beiseite gelegt wird, zumal sich das vorliegende Rezensionsexemplar wegen der dürftigen Herstellung schon nach einem zweiten In-die-Hand-nehmen zu zerlegen begann. 